\title{
Reuna
}

\section{QUALIDADE DE VIDA NO TRABALHO NAS MICRO E PEQUENAS EMPRESAS COMO VANTAGEM COMPETITIVA}

\author{
QUALITY OF LIFE AT WORK IN MICRO AND SMALL ENTERPRISES AS A \\ COMPETITIVE ADVANTAGE
}

http://dx.doi.org/10.21714/2179-8834/2016v21n4p81-102

\author{
Hamilton Pozo \\ Universidade Anhembi Morumbi, Brasil. \\ Endereço: Rua Casa do Ator , 275, Vila Olímpia, CEP 04546001 - São Paulo, SP - Brasil \\ Fone: +55 (11) 32927351 \\ Email: hprbrazil@hotmail.com - Lattes: http://lattes.cnpq.br/7082129428182587 \\ Elio Takeshy Tachizawa \\ Instituto de Ensino Campo Limpo Paulista S/C Ltda - SP, Brasil. \\ Endereço: Rua Guatemala, 167, Jardim América, CEP 13231-230 - Campo Limpo Paulista, SP - Brasil \\ Fone: +55 (11) 48129400 / Fax: (11) 48129400 \\ Email: usptakes@uol.com.br - Lattes: http://lattes.cnpq.br/5203729599096224
}

Submissão: 21 Out. 2015 Publicação: 30 Dez. 2016. Sistema de avaliação: Double blind review. Centro Universitário UNA, Belo Horizonte - MG, Brasil. Editor geral Prof. Dr. Mário Teixeira Reis Neto

Este artigo encontra-se disponível no endereço eletrônico:

Reuna: http://revistas.una.br/index.php/reuna/article/view/824

DOI - http://dx.doi.org/10.21714/2179-8834/2016v21n4p81-102

\section{RESUMO}

O presente trabalho visa ampliar a análise e reflexões sobre a aplicação da qualidade de vida no trabalho como fator de vantagem competitiva, em toda sua essência, no mercado em que as micro e pequenas empresas (MPEs) atuam e as implicações de um programa de qualidade de vida no trabalho implementado. $O$ método empregado foi de natureza exploratória de caráter quali-quantitativo, com a utilização de questões de múltipla escolha fundamentadas na escala tipo Likert agregada e com questões abertas na avaliação do modelo. Os resultados foram analisados com técnicas estatísticas. De um universo de 38 empresas no município de Jundiaí (SP), foram analisadas quatro empresas com uma amostra de 44 respondentes. O resultado obtido revelou que a preocupação com a Qualidade de Vida no Trabalho cada vez mais tem se mostrado como um elemento importante dentro das empresas pesquisadas.

Palavras-chave: Qualidade de vida no trabalho, Micro e pequenas empresas, Vantagem competitiva. 


\begin{abstract}
This work aims to expand the analysis and reflections on the application of quality of life work as a competitive advantage factor, in all essence, at the market in which micro and small enterprises operate and the implications of a quality of life work program is implemented. The method was exploratory in nature of qualitative and quantitative character, with the use of multiple-choice questions based on Likert scale, aggregate and open questions in the evaluation model. The results were analyzed using statistical techniques, rom a universe of 38 companies in the city of Jundiaí (SP), were analyzed 4 companies with a sample of 44 respondents. The result showed that concern for the Quality of Life at Work has increasingly been seen as an important element within the companies surveyed.
\end{abstract}

Keywords: Quality of life at work, Micro and small enterprises, Competitive advantage.

\title{
Introdução
}

Nas últimas décadas, têm-se desenvolvido técnicas e sistemas para lidar com a crescente complexidade dos problemas empresariais, quer em termos da sua formulação, quer no que concerne à sua resolução. $O$ contexto da competitividade mundial e das constantes mudanças que afetam as organizações tem exigido que o sistema educacional esteja pronto a apresentar respostas e a indicar caminhos capazes de romper antigos paradigmas da administração. Porém, em se tratando de mudança, já se cria certo ressentimento. A mudança em si é um processo complexo que desencadeia resistências em todos os sentidos. As pessoas sentem-se naturalmente incomodadas e forçadas a aceitar novos paradigmas. O grande desafio das MPEs, dentro da área operacional, é reconstruir em um meio competitivo, altamente tecnológico e acirrado, um sistema de bem-estar no sentido da Qualidade de Vida no Trabalho (QVT) para os colaboradores de uma organização, tomando como base os fatores biológicos, psicológicos e sociais de cada ser humano.

A revolução tecnológica, as mudanças no sistema produtivo e a globalização não foram capazes de resolver todos os problemas sociais e ambientais, colocando uma pauta de discussão que é a responsabilidade social das empresas e de como empreender nesse novo ambiente. Assim, buscando um desenvolvimento sustentável, muitas corporações passaram a empreender ações sociais na comunidade, abrangendo toda a cadeia de relacionamentos: funcionários, clientes, fornecedores, investidores, governo, concorrentes, acionistas e sociedade.

O presente trabalho visa ampliar a análise e reflexões sobre a aplicação da qualidade de vida no trabalho como fator de vantagem competitiva, em toda sua essência, no mercado em que as MPEs atuam. Apresentar um panorama dessas especificidades da QVT, numa tentativa de tipologia e distinção entre as ações decorrentes de sua aplicação e sua convergência e orientação para ganho de competitividade.

O tema qualidade de vida tem sido objeto de reflexão devido à busca de melhores condições de vida, não somente no contexto social, mas principalmente dentro das empresas. Portanto, devendo ser enfatizada a promoção da saúde, englobando 
diversos fatores que determinam a qualidade de vida dos funcionários para ganhos de produtividade focados numa visão empreendedora. Pode-se afirmar que a saúde é um dos principais parâmetros, porém há vários indicadores que visam quantificála. Investir em programas de promoção de saúde e qualidade de vida no trabalho proporciona considerável economia, em termos de reduções de custos de assistência médica, licenças-saúde e doenças ocupacionais, maior ênfase empreendedora e, principalmente, em ganhos de produtividade.

Esta abordagem permite, por exemplo, que se contemple uma maior possibilidade de desenvolvimento pessoal e empreendedor, facilitando o trabalho em equipe, uma maior harmonia entre a vida pessoal e profissional e melhor rendimento operacional. Essa qualidade de vida diferenciada que é percebida, tanto pela empresa como pelo funcionário, está ligada a um forte processo motivacional. Esse processo, decorrente de um programa de qualidade de vida no trabalho, passa a ter uma finalidade estratégica para a empresa, visto que esse programa é percebido pelos funcionários quando a empresa o implementa através de uma ação participativa, clara e objetiva com a participação e interveniência de todos.

Quando um funcionário percebe que está trabalhando em um local que Ihe proporcione prazer por estar com seu corpo em uma posição ergonométrica adequada, com condições de ventilação e iluminação correta, com procedimentos definidos, oportunidade de uso de sua capacidade e de seu crescimento, tende a empreender e inovar e, assim, produzir mais eficazmente. Com isso passa a ter sua integração social completa no trabalho, com o poder de tomar decisões, não sofrendo pressões que levam ao estresse, e com uma remuneração condizente ele estará imbuído de um forte elemento motivacional que se transforma em um diferencial competitivo e inovador, sendo uma ferramenta estratégica para a empresa.

Percebe-se neste contexto uma significante tendência de mudança que permeia as relações de trabalho e o emprego formal, exigindo um novo perfil de administrador, capacitado para identificar oportunidades de atuação e de negócios, empreender sua carreira e seus projetos, tornando-se um sujeito da história e um agente de mudança das organizações, fundamentado em um Programa Estratégico Operacional ligado à qualidade de vida percebida no trabalho. Assim, nesta visão será adotado como conceito de qualidade de vida no trabalho um conjunto de ações e atitudes dentro de uma organização que envolverá análise e implementação de melhorias e inovação empreendedora na gestão e na estrutura interna e externa do ambiente de trabalho com apoio de novas tecnologias, visando criar condições plenas de bem-estar do funcionário para a plena execução de seu trabalho operacional.

É necessário mudar os paradigmas e paralelos históricos encontrados, mais comumente, nos movimentos sociais românticos do início do industrialismo, levados por artesãos, plebeus e trabalhadores, nos movimentos de defesa da classe média popular. Nos movimentos oriundos da segunda metade do século XX, com o início da globalização, com a busca incontrolável e desmedida de ganhos de produtividade motivada pelos críticos burgueses da civilização comprometida por reformadores, modernistas e assim por diante. Möller (1997, p.126), renomado especialista em gestão de pessoas, já afirmava na década de 1990 que: 
Muitas empresas latino-americanas gastam mais na manutenção dos automóveis dos gerentes que no desenvolvimento de seu pessoale que, futuramente, as empresas competirão entre si não apenas pelos clientes, mas também pelos melhores recursos humanos.

A principal preocupação é que a qualidade dos produtos e serviços de uma empresa deva refletir e reflita a qualidade de vida de quem os produz. $\mathrm{O}$ conceito de qualidade de vida no trabalho é composto de diversos procedimentos empresariais que devem envolver a Gestão de Recursos Humanos, a Gestão de Operações e os Potenciais existentes para emitir sinais coerentes do que a alta administração da empresa valoriza; a cultura organizacional e o trabalho, que devem ser usados como uma ferramenta estratégica dentro da empresa. Portanto, o objetivo é demonstrar a forte correlação entre o trabalho motivado e a qualidade de vida percebida no ambiente empresarial que amplia o grau de comprometimento dos funcionários, sendo assim um elemento de ganho de produtividade e estratégico para a empresa.

Um projeto estratégico voltado para motivar os funcionários e alavancar o seu foco intra-empreendedor deve estar intimamente envolvido com o projeto de QVT para que as pessoas possam estar emocionalmente embaladas e acreditarem que também vão sair ganhando para poderem dar o melhor de si. Uma empresa não terá sucesso sem que seus funcionários tenham uma realização profissional. Portanto, é preciso definir visões de sucesso, de tal forma que haja uma coerência com os resultados esperados a respeito da iniciativa, produtividade, relacionamentos, qualidade pessoal e, por fim, as aptidões profissionais ou competência profissional.

Nesse aspecto é importante criar um novo modelo ou espaço para a reflexão sobre a forte condição da competição organizacional e a luta pela melhor competitividade com qualquer custo. O interesse específico, aqui, é analisar como as MPEs estão amplamente envolvidas na busca por maior produtividade e por uma mudança com o intuito de melhorar seu posicionamento competitivo no mercado. Assim, a QVT vem cada vez mais ganhando espaço nas discussões empresariais e acadêmicas e, também, nas MPEs.

A busca de uma vantagem competitiva acirrada leva as empresas a considerarem a qualidade de vida como um componente importante nas formulações de suas estratégias de gestão de pessoas para o pleno sucesso organizacional.

Incluir a abordagem em qualidade de vida como ferramenta de gestão estratégica de operações nas MPEs, diante do cenário econômico atual, constitui-se em grande desafio aos gestores de recursos humanos, saúde e benefícios. É neste sentido que os empresários devem ser norteados no processo de contemplar elementos fundamentais para o desenvolvimento de uma cultura de moderna de Gestão Estratégica Empresarial, que é essencial para o sucesso do negócio, atuando com suas competências e, assim, contribuir para ganhos de competitividade.

Portanto, ao se identificar os níveis de satisfação no trabalho, podem-se obter os fatores da QVT que estão afetando o desempenho dos funcionários, no que se refere à qualidade e produtividade dos produtos e serviços por eles gerados. Estes fatores, dependendo da forma como forem analisados, podem se constituir em referenciais para possíveis mudanças nos modelos de gestão das relações de trabalho e das estratégias a serem implantadas para galgar o caminho mais curto na direção da competitividade. 
A correlação existente entre ganho de competitividade e o bem-estar dos funcionários motivou esta pesquisa, pois, mesmo diante de um quadro econômico altamente instável e desfavorável para investimentos na área da QVT, não se pode furtar a este fato, em função da grande dependência do potencial humano para que as empresas se mantenham vivas no mercado com a obtenção de vantagens competitivas advindas dos resultados proporcionados por eles e de como poderão ajudar as MPEs.

\section{Referencial teórico}

\subsection{Micro e pequenas empresas}

As micro e pequenas empresas no Brasil são maioria, entretanto, mesmo assim, as informações sobre elas ainda são pouco exploradas por órgãos oficiais. Este fato acaba gerando dificuldade de direcionamento de recursos adequados à promoção destas empresas, o que se mostra incoerente, dada a importância desse segmento na economia e na vida diária da população (SEBRAE, 2013). As MPEs são responsáveis por absorver a maior parte da mão de obra, principalmente os jovens, pois geram renda, movimentam a economia e são extremamente importantes em função da sua capilaridade no país. Conforme aponta o SEBRAE (2014), estes portes de empresas correspondem a $99 \%$ do total de empresas existentes no país, geram $77 \%$ dos empregos, são responsáveis por $62 \%$ das exportações, pagam $40 \%$ da massa dos salários, correspondem a $28 \%$ do faturamento e têm $20 \%$ de participação no PIB.

Há pelo menos duas maneiras de se caracterizar as MPEs: por seu faturamento, conforme circulares no 11 e 34/2011 do Banco Nacional do Desenvolvimento Econômico e Social - BNDES, e pelo número de funcionários, como demonstrado na $T A B$ 1, de acordo com o critério operacional do Serviço de Apoio às Micro e Pequenas Empresas (2014):

Tabela 1 - Caracterização do porte das empresas por número de funcionários

\begin{tabular}{lll}
\hline PORTE & \multicolumn{2}{l}{ EMPREGADOS } \\
\cline { 2 - 3 } Microempresa & COMÉRCIO E SERVIÇO & INDÚSTRIA \\
\cline { 2 - 3 } Pequena empresa & Até 09 & Até 19 \\
Média empresa & de 10 a 49 & de 20 a 99 \\
Grande empresa & de 50 a 99 & de 100 a 499 \\
\hline
\end{tabular}

Fonte: Adaptado de SEBRAE (2014) 
As MPEs encontram diversas dificuldades em desenvolver estratégias por não possuírem recursos financeiros e investimentos em setores críticos que possam proporcionar maior competitividade. Vieira (2002) destaca que:

...estas têm várias origens, dentre as quais, a falta de recursos humanos capacitados, a falta de métodos estruturados e a complexidade das relações da empresa com o meio onde ela está inserida.

Apesar de as MPEs encontrarem grandes dificuldades em sua gestão, verificam-se algumas características, como: dinamismo, flexibilidade, inovação e simplicidade, que podem proporcionar fatores de sucesso para sua sobrevivência.

\subsection{Qualidade de vida no trabalho}

O conceito de QVT, embora possa parecer muito abrangente, necessita ter uma definição clara e objetiva, uma vez que as posições profissionais dos trabalhadores dentro de uma organização são meios de satisfazerem suas necessidades de toda ordem, com reflexos evidentes em sua qualidade de vida. Esta última baseia-se em uma visão integral das pessoas, que é o chamado enfoque biopsicossocial, o qual propõe a vida integrada do ser humano com o trabalho e sua atividade social.

A partir do momento em que o ser humano é visto como um todo, passa a haver a visão biopsicossocial. O ser humano tem potencialidades biológicas, psicológicas e sociais para enfrentar a vida cotidiana. Essa combinação funciona interligada e não departa mentalizada. Pode-se perceber então que, para alguns autores, não apenas as condições físicas de trabalho são as que influenciam a QVT, porém é de suma importância que se considerem outros fatores, tais como as relações entre o indivíduo e os indivíduos, seu trabalho, a organização onde desenvolve esse trabalho e a própria sociedana qual está envolvido. Portanto, o ser humano deve ser a peça central de um programa de QVT, e não uma mera ferramenta. O nível biológico refere-se às características físicas herdadas ou adquiridas ao nascer e durante toda a vida, envolvendo seu metabolismo, resistências e vulnerabilidades de seus órgãos.

E é no nível social que se revela a importância de como os valores correspondentes às crenças, ao papel na família, ao papel no trabalho e na comunidade a que cada pessoa pertence e atua para seu bom desempenho. E no meio ambiente, que é a posição geográfica, também formam o dimensional social. Com relação ao nível psicológico, este se refere aos processos afetivos, emocionais e de raciocínio, conscientes ou inconscientes, que formam a personalidade de cada pessoa e o seu modo de ver e perceber perante o ambiente e, assim, posicionar-se diante das pessoas e das circunstâncias que vivencia.

Para Walton (1974), a expressão Qualidade de Vida tem sido usada com crescente frequência para descrever certos valores ambientais e humanos, negligenciados pelas organizações que estão preocupadas exclusivamente com 0 avanço tecnológico e da produtividade. Considera a QVT como resultante direta da combinação de diversas dimensões básicas do desempenho das atividades, e de outras dimensões não dependentes diretamente das tarefas, capazes de produzir motivação e satisfação nos diferentes níveis, atividades e condutas das pessoas dentro das organizações. 
A QVT deve ser tratada como um processo pelo qual uma organização tenta revelar o potencial criativo de seu pessoal, envolvendo-o em decisões que afetam sua vida no trabalho. Uma característica marcante do processo é que seus objetivos não são simplesmente extrínsecos, focando melhora da produtividade e eficiência em si; eles também são intrínsecos no que diz respeito ao que o trabalhador vê como fins de autorrealização e autoengrandecimento pessoal e profissional.

De acordo com Sant'anna, Moraes e Kilimnik (2005, p.6), por sua vez:

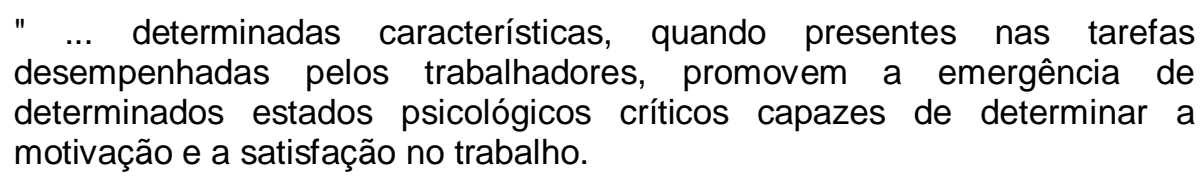

Qualidade de vida no trabalho nos dias atuais é entendida como a capacidade de administrar as turbulências do mercado competitivo, com mudanças nos hábitos pessoais e dos processos de trabalho, com foco no bem-estar do dia a dia e na longevidade, mantendo uma excelente saúde biopsicossocial.

Seguindo essa interpretação, observa-se que surge uma forte tendência, dentro do setor acadêmico e de algumas empresas, para a percepção de que o posicionamento firme e duradouro de uma organização no mercado globalizado tenha que passar pela ótica de que os funcionários tenham uma qualidade de vida melhorada. Portanto, investir em programas de promoção de saúde e qualidade de vida no trabalho irá proporcionar considerável economia, em termos de reduções em custos de assistência médica, licenças-saúde e doenças ocupacionais e, principalmente, em ganhos de produtividade.

Para superar este positivismo ingênuo e ilusório criado por barreiras para se ter um novo posicionamento do homem em seu trabalho, deverá tornar-se claro o significado das palavras usadas, situando-as em uma armação intelectual mais geral de referência. Não é só explicar o "que eu penso", mas sim comparar as próprias categorias da pessoa com os tipos de construção da realidade social que se deseja.

As inovações de gestão afetam a cultura da empresa e não devem ser tratadas como conflitos. Um conflito pressupõe uma definição clara de oponentes ou atores que competem e dos recursos pelos quais estão lutando ou negociando para terem controle. Um programa de qualidade de vida deve ter uma definição clara e objetiva de seus propósitos e deixar de modo aberto a todas as aproximações e vertentes para seu pleno êxito.

Segundo Albuquerque e França (1998, p.40-51): A qualidade deve ser gerenciada junto com a qualidade de vida. Os esforços empresariais devem, em última instância, conduzir à realização humana, ou seja, a qualidade só terá sentido se gerar qualidade de vida. No entanto, existe uma grande distância entre o discurso e a prática do que seria o bem-estar das pessoas. Esforços e competências estão adquirindo novos significados. As mudanças ocorrem tanto no foco estratégico como na gestão do negócio com um todo e no envolvimento das pessoas. Essas mudanças demonstram o aumento da responsabilidade estratégica dos gestores de Recursos Humanos.

É importante salientar que a participação nos problemas decisórios que lhes dizem respeito, bem como a posse de informações em relação ao posto que ocupem são 
os fatores mais frequentemente mencionados pelos autores, para elevar-se o nível de participação dos empregados.

Segundo Conte, (2003), a implantação da QVT pode ser vista como um programa que visa facilitar e satisfazer as necessidades dos funcionários no desenvolvimento de suas atividades dentro de uma empresa, tendo como base o fator de que as pessoas são mais produtivas quanto mais estiverem satisfeitas e envolvidas com o seu próprio trabalho.

Pressionados por mudanças tecnológicas, gerenciais, legais e demográficas, as empresas e os funcionários buscam novas demandas e atenções específicas. Por força do próprio trabalho, do desenvolvimento profissional e para uma transição para a aposentadoria, percebe-se quão importantes são as características específicas do desenvolvimento humano na elaboração deste projeto. Neste sentido, a Qualidade de Vida e a Qualidade de Vida no Trabalho se complementam, como proposto no modelo de qualidade de vida ao longo do curso de vida, conforme Myers e Sweeney (2007).

Mudar os paradigmas e paralelos históricos já vivenciados nos movimentos sociais e dos negócios que envolvem os trabalhadores e suas lutas por melhorias devem ser levados em consideração em todos os movimentos nesse sentido para a melhoria de seu bem-estar.

Com esta pesquisa, pretende-se desenvolver um plano de agentes de Qualidade de Vida no Trabalho que ajudem na resolução de problemas de motivação, ergonometria, desempenho, satisfação, crescimento, atuação, dinâmica e stress pessoal em ambientes organizacionais, mas principalmente nas MPEs.

\subsection{Estratégias competitivas}

Estratégia, segundo Mintzberg (2010), trata-se da "forma de pensar no futuro, integrada no processo decisório, com base em um procedimento formalizado e articulador de resultados". Segundo Porter (2005), a estratégia depende fundamentalmente do posicionamento que a empresa pretende para se alinhar com a estrutura do setor. A estratégia deve alinhar as forças da empresa de acordo com as oportunidades verificadas e/ou detectadas no setor, orientando a empresa para explorar as oportunidades. Segundo Prahalad, (2004), a estratégia deve ser baseada no interior da empresa. São as suas competências nucleares, os seus saberes, o alinhamento dos seus elementos que vão permitir à empresa ser e atuar de forma diferente, permitindo assim inovar e criar uma vantagem competitiva.

Para esta pesquisa elencamos o conceito de Contador (2008. p.74), que define as seguintes tipologias de estratégias:

Estratégia corporativa é a estratégia relativa à corporação como um todo e só aplicável àquela que possui mais de uma empresa ou de um negócio. Estratégia de negócio é a estratégia de uma empresa ou de uma unidade de negócio para o posicionamento de um produto num mercado.Estratégias operacionais ou funcionais são as estratégias internas à empresa relativas aos seus departamentos ou às suas áreas funcionais. 
Entre os pensadores das diversas correntes da Teoria da Competitividade, existe um ponto de concordância sobre a competitividade de negócio, por exemplo, que ela poderá ser medida por um indicador de rentabilidade ou de participação de mercado. Contudo, pode-se supor que competitividade empresarial significa a obtenção de uma rentabilidade igual ou superior aos rivais no mercado. Se a rentabilidade de uma empresa, numa economia aberta, é inferior à dos seus rivais, embora tenha com que pagar os seus trabalhadores, fornecedores e acionistas, em médio ou longo prazo estará debilitada até chegar a zero e tornar-se negativa.

No âmbito da diversidade de conceitos existentes sobre competitividade, elenca-se o conceito de Contador. Na sua definição (2008; p.74):

\begin{abstract}
Competitividade é a capacidade da empresa em obter resultado sustentável superior ao das concorrentes, medido por um indicador de crescimento de mercado e assegurada uma rentabilidade satisfatória, por meio do alcance de uma ou mais vantagens competitivas. Se uma empresa obtém melhor resultado que uma concorrente, ela é mais competitiva. O modelo CAC dá um critério bastante seguro para a empresa ser competitiva, expresso sob a forma de tese: "Para a empresa ser competitiva, basta ter excelência apenas naquelas armas que the dão vantagem competitiva nos campos escolhidos para competir em cada par produto/mercado."
\end{abstract}

Sobre os indicadores de competitividade, há duas linhas básicas de pensamento: competitividade como causa de desempenho superior da empresa e competitividade como o próprio desempenho superior.

Os alinhados à escola da Visão Baseada em Recursos (Resource-Based View $R B V$ ) entendem que a competitividade é consequência dos recursos e ações da empresa - são os recursos e ações da empresa que determinam sua competitividade, de acordo com Barney (1991). São recursos e capacitações que promovem vantagem competitiva para a empresa. A fonte de vantagem competitiva deixa de estar no posicionamento da empresa no mercado de oferta e procura para estar dentro da própria empresa. O que importa para o negócio é o acesso a determinados recursos, e não sua posição nas relações de poder com as outras forças competitivas, como sugeria Porter (2005).

Outra ferramenta para identificar as competências essenciais é a análise da Cadeia de Valor conforme Porter (2005), para saber onde aplicar a competência essencial. O modelo de Porter é exclusivamente de posicionamento. Importa a posição que a empresa pretende ocupar dentro do seu setor, considerando a posição de seus concorrentes. Para decidir, não leva em consideração as forças internas da instituição (competências internas). Este modelo busca identificar em qual indústria (ou setor) atuar e qual a posição relativa que poderá ocupar dentro dessa indústria. Para isso, analisa três possíveis estratégias genéricas: Liderança em custo, Diferenciação e Foco. 


\section{Método}

Houve delineamento exploratório aplicado, por meio de vertente quali-quantitativa, pelo método do estudo de caso, com a coleta dos dados viabilizada pela técnica da entrevista, tendo como instrumento a Escala de Likert ampliada com questões abertas.

Do ponto de vista teórico, ela explora, na literatura pertinente, concepções, teorias e princípios relacionados ao problema. Sua natureza é a de uma pesquisa aplicada, pois o que se pretende mostrar é a forma como os conhecimentos pertinentes ao tema foram utilizados, ou não, numa determinada situação e na solução de problemas específicos. $O$ delineamento da pesquisa consiste em tornar o problema pesquisável e especificar como a amostra será extraída, quais subgrupos deverão conter, quais comparações serão feitas, se serão necessários grupos de controle, quais variáveis serão mensuradas (quando e em quais intervalos) e como estas medidas serão relacionadas a eventos externos.

Momentos metodológicos percorridos para o desenvolvimento da pesquisa exploratória aplicada:

- Definição do objeto de estudo;

- Levantamento bibliográfico em base de dados operacionais e disponíveis usando os descritores obtidos;

- Delimitação do universo e da amostra, do método, da técnica e instrumento de coleta de dados;

- Realização dos procedimentos éticos para a coleta de dados;

- Tratamento dos dados da escala e das questões abertas;

- Análise e interpretação dos dados, tendo como referência os objetivos e os conceitos do marco teórico;

A pesquisa de campo foi desenvolvida em quatro MPEs industriais localizadas na Região de Jundiaí. O instrumento utilizado na coleta de dados foi entrevista e, para sua elaboração, foram considerados critérios como a possibilidade de obtenção de dados diretamente do aplicador, privilegiando-se a entrevista fechada com escala Likert e questões abertas, que possibilitem respostas livres com espaços para explicações e comentários. De 63 questionários, foram respondidos 44, que proporcionaram os dados da pesquisa. Como referencial à formulação do questionário, foram consideradas as perguntas que impulsionam essa pesquisa e os objetivos gerais e específicos anteriormente apresentados. A razão fundamental de opção por este método é a complexidade do problema em estudo. Não se trata de medir objetos, mas sim de descobrir a natureza das experiências das pessoas com respeito aos fenômenos condizentes à responsabilidade com que deve ser tratada a vida humana, seus valores, suas decisões. Os questionários foram aplicados diretamente com os funcionários envolvendo pessoal de chão de fábrica, pessoal de escritório e a gerência. 
Para o atendimento dos objetivos desta pesquisa, é necessária a análise dos fatores de influência sobre o interesse sobre a qualidade de vida no trabalho e do empreendedorismo. No trabalho de Baughn et al. (2006), foram analisados os seguintes fatores à qualidade de vida: influência do contexto; capital social; e domínio das habilidades sobre QVT.

Quanto ao contexto para análise, foram avaliadas no estudo original as perspectivas de diferentes empresas analisadas pelo autor, e considerou-se consistente a fundamentação de avaliar as empresas da região de Jundiaí. A partir das proposições, desenvolveu-se um estudo empírico para validação por meio de técnicas estatísticas adequadas. Os procedimentos e decisões estão expostos a seguir. A partir dos procedimentos e especificamente sobre as escalas dos construtos, todas as variáveis foram extraídas e traduzidas de Baughn et al. (2006), com algumas adaptações.

Após a consolidação preliminar do instrumento, foi feito um pré-teste (uma pesquisa piloto) junto a uma amostra de 9 respondentes. Feitos os devidos ajustes, o questionário foi aplicado. Nesta fase foram estabelecidas as configurações conforme exposto a seguir; o universo da pesquisa: constituído por funcionários de 4 MPEs industriais da Região de Jundiaí (São Paulo); o tamanho atual deste universo: aproximadamente 38 empresas de manufatura e serviço, aproximadamente 643 funcionários; a amostra: foi selecionada uma amostra de 63 respondentes, porém somente 44 responderam ao questionário; a coleta de dados foi procedida diretamente pelos próprios pesquisadores. Os critérios de seleção foram conveniência e acessibilidade.

Procurou-se mensurar a satisfação dos empregados com relação ao programa de gestão da qualidade de vida no trabalho, relacionando seus valores pessoais e os resultados esperados na empresa. Os dados foram obtidos na Escala Likert de 0 a 5 , onde 0 significava totalmente insatisfeito e 5 totalmente satisfeitos. As principais questões colocadas para cada empresa foram:

- Você percebe que a empresa tem um programa de Gestão de QVT?

- As Ações e os Programas de Gestão da QVT na Empresa são importantes?

- Os empregados valorizam as ações e os programas da Gestão de QVT na empresa?

- Minha participação nos programas de Gestão da QVT é:

- Você percebe que os gerentes tratam os Programas de QVT como uma estratégia?

- As ações e os programas de Gestão da QVT produzem melhorias na produtividade da empresa?

- A Gestão da QVT na empresa permite medir a melhoria do desempenho das equipes de trabalho?

- O programa de Gestão da QVT é uma ferramenta para o Plano Estratégico da empresa? 
- Você é considerado pela empresa como uma pessoa importante para que ela atinja os objetivos?

- Um programa de Gestão da QVT poderá ser um fator que proporcione maior competitividade para empresa?

\section{Análise e resultados}

Os procedimentos estatísticos para os dados coletados na pesquisa de campo foram: descrição da amostra; análise uni variada dos construtos; e análise multivariada, com a avaliação das hipóteses definidas. O tratamento estatístico dos dados foi realizado com o software SPSS-18, apoiando-se em Hair et al. (2005) e Malhotra (2001). A análise fatorial foi utilizada neste estudo por ser considerada uma técnica útil para analisar conjuntos de variáveis relacionadas que possuam interdependência. $O$ agrupamento de variáveis, ou fator, permite identificar dimensões subjacentes que explicam a correlação entre as variáveis. Alguns cuidados antecedentes à análise fatorial foram necessários, como a realização do teste de esfericidade de Bartlett, valor de $\mathrm{KMO}$ e adequação dos itens à análise fatorial, por meio da verificação dos valores obtidos na matriz anti-image (HAIR et al., 2005).

O teste de esfericidade de Bartlett revelou-se significante em um nível de $1 \%$, com um valor de quiquadrado de aproximadamente 273,5; valor de $\mathrm{KMO}=0,657$. Os valores obtidos para os MSA's - measure sampling adequacy - que identificam a adequação de cada item ao modelo de análise fatorial, resultantes da matriz antiimage, foram superiores a 0,55 . Utilizando-se o critério de Kaiser, que considera os valores de eigenvalue superiores a 1,0 (HAIR et al., 2005) foram encontrados cinco fatores, explicando $61,1 \%$ da variância total.

Elaborou-se um banco de dados a partir dos questionários respondidos, para posterior tratamento e análise dos resultados. Para garantir a confiabilidade e a consistência interna dos dados obtidos, realizou-se o cálculo do alfa de Cronbach, o qual resultou em 0,73 e, portanto, acima do recomendado, que corresponde a 0,6 (MALHOTRA, 2001).

Com relação à análise uni variada, inicialmente foram extraídas as médias e os desvios-padrão de cada uma das variáveis. Com a confirmação da estrutura dos itens na composição dos construtos, foi extraída uma medida geral por construto, com agregação dos escores pela média das entradas dos itens componentes de cada construto. Considerando que as hipóteses supõem estar relacionadas com os construtos, optou-se por avaliar estes relacionamentos por meio da ferramenta Análise de Regressão Múltipla. Essa ferramenta viabiliza a avaliação da consistência da relação de influência entre duas ou mais variáveis independentes, e uma variável dependente (MALHOTRA, 2001). Assim, as quatro hipóteses foram testadas e tendo como variável dependente o construto interesse, e como variáveis independentes os construtos apoio, domínio, normas e propriedade.

Com os resultados disponibilizados, optou-se por avaliar os construtos, considerando as diferentes alternativas de resposta de algumas das variáveis do estudo, como forma de identificar e discutir possíveis diferenças. Conforme Malhotra 
(2001), tal procedimento é viabilizado pela técnica estatística análise de variância (ANOVA). Os elementos analisados nesta pesquisa foram extraídos de quatro MPEs industriais localizadas na Região de Jundiaí que possuem programa de gestão da qualidade de vida no trabalho. Utilizou-se para a coleta de dados um formulário autopreenchível com escala Likert, que foi aplicado pessoalmente a cada funcionário em cada empresa. Os resultados aqui expressados se referem às respostas de 44 questionários respondidos na presença dos pesquisadores para maior validade e confiabilidade das respostas:

- Dados gerais dos funcionários, sendo de ambos os sexos e atuando em funções de operação, técnica, de supervisão e gerencial com 44 respondentes ao todo;

- A percepção do conceito de qualidade de vida no trabalho vista pelos funcionários e sua sensibilidade aos fatores empregados pela empresa;

- QVT como diferencial estratégico para melhoria de produtividade, como os funcionários sentem esse novo paradigma e como interpretam;

- Desenvolvimento pessoal com a gestão da qut e o contexto da empresa.

As medidas obtidas mostram que as questões que discutiam a percepção dos funcionários quanto à interpretação do programa de gestão da qualidade de vida no trabalho praticado pelas empresas foram regulares.Quanto às questões referentes à qualidade de vida no trabalho como um diferencial estratégico na percepção dos funcionários, obteve-se notas altas.Com relação ao desenvolvimento dos funcionários com os programas de qualidade de vida no trabalho, a percepção de todos foi altíssima.

O universo dos respondentes foi constituído por funcionários das quatro empresas escolhidas componentes do universo de 38 MPEs da Região de Jundiaí. Os resultados da pesquisa e seus dados seguem abaixo, sendo os primeiros cinco referentes aos dados de caracterização dos funcionários que responderam ao questionário, conforme quadro 1, abaixo: 


\begin{tabular}{|c|c|c|c|}
\hline Sexo dos fimcionários & $\%$ & Nivel hierárquico. & Anos \\
\hline Masculino & 75 & \multirow{3}{*}{$\begin{array}{l}\text { Operacional } \\
\text { Técnico } \\
\text { Cerencia }\end{array}$} & \multirow{3}{*}{$\begin{array}{c}27 \\
9 \\
59 \\
\end{array}$} \\
\hline Feminino & 25 & & \\
\hline siturän familiar & 8 & & \\
\hline Solteiro & 18 & \multirow[t]{2}{*}{ Superior } & \multirow[t]{2}{*}{9} \\
\hline Casado & 82 & & \\
\hline & & Área de atuaçâo & Anos \\
\hline Tempo na empresa & Anos & \multirow{2}{*}{$\begin{array}{l}\text { Auxiliar } \\
\text { Financas }\end{array}$} & \multirow{2}{*}{$\begin{array}{l}37 \\
27\end{array}$} \\
\hline Até 3 anos & 9 & & \\
\hline De 4 a 8 anos & 18 & \multirow{2}{*}{$\begin{array}{l}\text { Marketing } \\
\text { Produçấo }\end{array}$} & \multirow{2}{*}{$\begin{array}{l}9 \\
27\end{array}$} \\
\hline Mais de \& anos & 73 & & \\
\hline
\end{tabular}

Quadro 1. Dados dos funcionários

Fonte. Dados da pesquisa

Os resultados a seguir se referem aos dados que tratam sobre a percepção dos funcionários quanto ao seu desenvolvimento pessoal para melhoria da qualidade de vida no trabalho e sua melhor atuação com ganho de eficácia na estratégia da empresa para ganho de competitividade, conforme TAB 2, abaixo.

Tabela 2. Percepção dos funcionários

\begin{tabular}{lllllll}
\hline CONDIÇÕES & \multicolumn{7}{l}{ Nada } & Pouco & Regular & Muito & Bastante \\
\hline Percepção do programa de QVT & 0 & 27 & 27 & 28 & 18 \\
Os empregados valorizam o programa QVT & 0 & 18 & 37 & 27 & 18 \\
Modelos gerenciais estratégicos para QVT & 9 & 27 & 27 & 28 & 9 \\
Medição de desempenho das equipes de QVT & 9 & 18 & 37 & 18 & 18 \\
Gestão do QVT e estratégias & 8 & 12 & 26 & 24 & 30 \\
Gestão do QVT e desenvolvimento pessoal & 5 & 7 & 20 & 30 & 38 \\
Ações do programa do QVT são importantes & 9 & 27 & 37 & 0 & 27 \\
Importância da participação no programa QVT & 9 & 9 & 46 & 18 & 18 \\
Melhorias e produtividade obtidas com QVT & 9 & 18 & 27 & 18 & 28 \\
QVT como ferramenta para o plano estratégico & 9 & 9 & 36 & 37 & 9 \\
\hline
\end{tabular}

Fonte. Dados da pesquisa

Com Análise Fatorial Exploratória, as variáveis de cada um dos construtos foram submetidas à técnica estatística que proporcionou a comparação com a proposta previamente definida e os resultados efetivamente encontrados a partir do trabalho de campo. Com relação aos construtos Percepção do programa de QVT na REUNA, Belo Horizonte - MG, Brasil, v.21, n.4, p.8I-IDZ, Dut. - Dez. 2016 - ISSN 2179-8834 
empresa,As ações do programa de QVT são importantes, Os empregados valorizam o programa de QVT e QVT como ferramenta para o Plano Estratégico da Empresa, a avaliação fatorial obtida manteve a expectativa previamente definida, não havendo a necessidade de qualquer ajuste.

Nas variáveis associadas aos Modelos gerencias estratégicos para QVT, Melhorias e produtividade obtidas com os programas de QVT e Medição de desempenho das equipes com os programas de QVT a Análise Fatorial Exploratória fez surgir dois fatores distintos das variáveis inicialmente submetidas à análise. A verificação das variáveis indicou que estas se agrupavam de modo a evidenciar dois tipos específicos de condições, que foram então identificadas por condição para a inovação e condição para o bem-estar no ambiente de trabalho.

Pelos resultados obtidos, pode-se verificar o seguinte: As médias das variáveis de interesse pessoal em QVT podem ser consideradas intermediárias, com desvios relativamente altos. As maiores médias foram verificadas nas variáveis que inquiriam sobre percepção, participação e interesse, podendo ser consideradas altas, acima de 4. As variáveis relacionadas ao negócio em si apresentaram médias menores. Com relação aos desvios, estes podem ser considerados como intermediários. Em geral, os desvios podem ser considerados de intermediários a altos, indicando uma dispersão relativamente elevada na avaliação dos funcionários. Homogênea foi a percepção de domínio de fator estratégico, com valores intermediários para as médias e desvios. Todas elas com valores relativamente próximos, entre 3,55 a 3,89 para médias, e desvios-padrão entre 0,90 a 1,03. Com esses dados, conclui-se que, em geral, os funcionários consideram boas as condições para a avaliação de nível estratégico para QVT nas empresas. Por fim, com relação à percepção de desenvolvimento pessoal que apresenta maior variação nas médias, variando entre 3,69 e 4,33. Os desvios, também, oscilaram entre 0,69 e 1,03. A indicação foi de que os funcionários se sentem bastante seguros quanto à possibilidade de desenvolvimento do pessoal e do negócio.

Com o índice Alpha de Cronbach as variáveis foram analisadas em sua confiabilidade para representar os construtos. O índice foi extraído para cada construto, chegando-se a valores aceitáveis, todos acima de 0,6. Com os resultados da estrutura fatorial encontrada, e da confiabilidade extraída, optou-se pela composição das variáveis para gerar uma medida geral de cada construto.

Foi tomada como regra de composição a média dos escores das entradas na planilha correspondentes para cada um dos construtos. Os resultados para os valores do índice Alpha da média e do desvio-padrão de cada um dos construtos estão mostrados abaixo. E conforme é possível verificar na TAB 3, as médias dos construtos apresentam valores entre intermediários e altos e os desvios-padrão podem ser considerados médios. 
Tabela 3: Resultados das médias dos construtos

\begin{tabular}{llll}
\hline CONDIÇÕES & Alpha & Média & $\begin{array}{l}\text { Desvio } \\
\text { padrão }\end{array}$ \\
\hline Percepção do programa de QVT & 0,858 & 3,42 & 0,99 \\
Os empregados valorizam o programa QVT & 0,779 & 3,99 & 0,76 \\
Ações do programa do QVT são importantes & 0,858 & 3,77 & 0,79 \\
Importância da participação no programa QVT & 0,679 & 3,66 & 0,69 \\
Modelos gerenciais estratégicos para QVT & 0,835 & 3,91 & 0,89 \\
Melhorias e produtividade obtidas com QVT & 0,829 & 3,88 & 0,88 \\
Medição de desempenho das equipes de QVT & 0,666 & 3,76 & 0,66 \\
QVT como ferramenta para o plano estratégico & 0,888 & 3,99 & 0,92 \\
Investimento em capacitação e melhorias (QVT) & 0,833 & 3,87 & 0,91 \\
Condições ambientais de trabalho e bem-estar & 0,699 & 3,81 & 0,71 \\
Condições para inovação & 0,858 & 3,91 & 0,88 \\
Gestão do QVT como fator de competitividade & 0,891 & 3,95 & 0,91 \\
\hline
\end{tabular}

Fonte. Dados da pesquisa

Pelo resultado das médias apresentadas, é possível perceber com maior clareza o posicionamento dos funcionários em relação aos construtos de referência ao desenvolvimento de práticas de estímulo ao desenvolvimento da QVT, que trata fundamentalmente de atividades associadas ao universo dos negócios.

As hipóteses definidas para o estudo foram avaliadas através de Análise de Regressão Múltipla, uma vez que esta viabiliza a avaliação da influência simultânea dos fatores definidos. Assim, o construto valorização do programa de QVT foi colocado na condição de dependente, ao passo que vocação percebida na área, percepção de suporte, domínio das habilidades (estas na mesma escala da variável dependente) e modelos gerencias e gestão da QVT (como uma dummy com 0 para não posse e 1 para posse) foram inseridas como independentes.

Os valores do modelo de regressão estimado encontram-se na TAB 4. O modelo pôde ser considerado consistente $\left(R^{2}=0,381\right)$ e, como é possível verificar, apenas os construtos associados à medição de desempenho das equipes, modelos gerenciaise condições ambientais do trabalho não apresentaram influência significativa, mostrada na significância da estatística $t$ para os coeficientes padronizados. 
Tabela 4: Resultados da regressão múltipla

\begin{tabular}{llll}
\hline CONDIÇÕES & $\begin{array}{l}\text { Coeficiente } \\
\text { padronizado }\end{array}$ & $\begin{array}{l}\text { Estatistica } \\
\boldsymbol{t}\end{array}$ & $\begin{array}{l}\text { Sig (p- } \\
\text { valor) }\end{array}$ \\
\hline Percepção do programa de QVT & 0,181 & 2,266 & 0,022 \\
Os empregados valorizam o programa QVT & 0,402 & 4,809 & 0,009 \\
Ações do programa do QVT são importantes & 0,155 & 1,356 & 0,441 \\
Importância da participação no programa QVT & 0,277 & 3,991 & 0,608 \\
Modelos gerenciais estratégicos para QVT & 0,099 & 1,088 & 0,797 \\
Melhorias e produtividade obtidas com QVT & 0,221 & 3,676 & 0,022 \\
Medição de desempenho das equipes de QVT & 0,078 & 0,989 & 0,499 \\
QVT como ferramenta para o plano estratégico & 0,203 & 3,871 & 0,211 \\
investimento em capacitação e melhorias (QVT) & 0,421 & 4,978 & 0 \\
Condições ambientais de trabalho e bem-estar & 0,111 & 1,099 & 0,773 \\
Condições para inovação & 0,377 & 4,079 & 0 \\
Gestão do QVT como fator de competitividade & 0,402 & 3,688 & 0 \\
\hline Fonte. Dados da pesquisa
\end{tabular}

Fonte. Dados da pesquisa

Com os resultados obtidos e mostrados acima, é possível depreender que a percepção de um programa de QVT dentro de uma empresa é fator de influência para o desempenho estratégico das pessoas e da organização. Para poder desenvolver uma maior contemplação e exploração dos dados, as medidas dos construtos foram avaliadas em relação a algumas das variáveis importantes que foram utilizadas na pesquisa e com o uso da ANOVA (técnica estatística análise de variância), que permite testar a existência de diferenças significativas nos valores médios das diferentes alternativas de resposta para as questões avaliadas.

As empresas para atingir seus objetivos, além de seguirem as exigências da Legislação vigente, deverão, cada vez mais, preocupar-se com a implantação de projetos que façam parte da administração estratégica da organização. A qualidade de vida do trabalhador deve ser encarada como um novo elemento estratégico da empresa para proporcionar e atingir plena satisfação. A busca da produtividade com qualidade tem sido um dos principais objetivos das empresas que pretendem sobreviver no atual cenário mundial, marcado por rápidas e profundas mudanças tecnológicas. Vive-se, portanto, numa sociedade altamente competitiva, onde a qualidade dos produtos e serviços oferecidos aliada a uma produtividade com qualidade constitui-se como um diferencial estratégico. Esse diferencial consolida a necessidade de uma visão integrada de gestão da QVT e a gestão empresarial para melhorias contínuas.

O comprometimento das pessoas é cada vez mais necessário, e as organizações necessitam estimulá-lo em seus funcionários, mas não sabem como. O indivíduo deverá ser o foco principal da função organizacional. São as pessoas que garantem o nível de flexibilidade, o grau e a velocidade de adaptação da empresa, que agregam valores aos produtos $e$ aos serviços em termos de qualidade $e$ produtividade e que respondem pelo processo de aprendizagem e pelo grau de inovação na organização. 
Isso tem levado muitas empresas a reverem suas estratégias e formas de gestão de pessoas, pois fica claro que "não há organizações estrategicamente vencedoras sem trabalhadores estrategicamente vencedores", conforme mostra Burigo (1997, p.184).

Assumir uma postura vigilante contra todas as práticas de desumanização no trabalho, através da implantação de um programa estratégico de qualidade de vida no trabalho, e atuando sobre estas, proporcionando assim melhores condições de vida aos trabalhadores. Contribui-se, assim, para a formação do trabalhador e para que ele possa viver melhor com a sua própria. Partindo do princípio de que as pessoas passam a maior parte de suas vidas nas organizações, seria ideal que estas fossem lugares mais aprazíveis e saudáveis para a execução do trabalho, onde os funcionários possam, de fato, passar algumas horas criando e realizando plenamente, com satisfação e alegria.

\section{Conclusões}

O estudo realizado proporcionou informações as quais revelam que a preocupação com a Qualidade de Vida no Trabalho, cada vez mais, tem se mostrado como um elemento importante dentro das organizações e tem crescido, também, nas MPEs. Isto conduz à visão de duas vertentes importantes: uma relacionada com o bemestar médico do funcionário e sua atuação na empresa, e a outra com a expansão do conceito de Qualidade de Vida no Trabalho em um ambiente fortemente competitivo e globalizado. Assim, torna-se necessária uma nova postura dos executivos e dos gestores de pessoas dentro das organizações, colocando as atividades de QVT como um elemento estratégico para recursos humanos e, principalmente, para as empresas.

Embora se perceba que os programas de QVT nas empresas pesquisadas estejam, ainda, com ações na área operacional limitadas, a maioria dos funcionários e dos gestores consideram que a gestão da QVT é uma ferramenta importante para o progresso dos funcionários e da própria empresa. Assim, esse desenvolvimento gera maior motivação dos funcionários, proporcionando o incremento da produtividade, a redução de custos e, portanto, ganhos fortes de competitividade. As empresas pesquisadas, embora de porte pequeno, têm uma posição boa nos mercados em que atuam resultante da atuação de seus colaboradores.

O estudo apresentado foi de natureza exploratória, quantitativa, com 15 questões em escala Likert. Os estudos estatísticos mostraram que $68 \%$ dos colaboradores entrevistados têm forte percepção da importância do programa de Qualidade de Vida no Trabalho, que é muito importante para as empresas e para o seu próprio desenvolvimento profissional e pessoal. Com relação à percepção do QVT como um diferencial estratégico e que propicia maior competitividade empresarial, $52 \%$ dos entrevistados concordam com esse fundamento. $O$ estudo demonstrou ser possível a relação entre estratégias de competitividade e programas de QVT.

Como o trabalhador é o elo diferenciador que impulsiona as organizações para o sucesso, faz-se necessário que as estratégias e formas de gestão das organizações proporcionem aos funcionários um comprometimento com as metas da organização onde atuam, fundamentadas em um programa de qualidade de vida no trabalho. 
Este comprometimento é obtido com um plano estratégico que envolva um pacote de melhorias contínuas envolvendo aspectos de maior segurança no emprego, mais benefícios, treinamentos e educação; melhores salários, relacionamento entre líderes, liderados e colegas, melhor ambiente físico de trabalho, ferramentas e máquinas de trabalho, plano de carreira e participação nos lucros e nas decisões, definidos pela literatura como sendo indicadores de qualidade de vida no trabalho. Um planejamento de práticas saudáveis voltadas para o bem-estar das pessoas proporciona para as MPEs melhor desempenho e vantagem competitiva.

Este trabalho buscou levantar dados sobre o desenvolvimento de programas de QVT nas Micro e Pequenas Empresas baseados na pesquisa e abordagem desenvolvida nas empresas descritas acima, considerando-se um universo reduzido para generalizar sobre o fato em questão. Deste modo, a primeira limitação consiste na impossibilidade de realizar generalizações para todo o setor de MPEs em escopo geográfico ampliado, bem como para outros setores de atividade. Sugere-se, assim, a reaplicação deste trabalho em outros contextos de negócios, seja envolvendo produtos ou serviços, seja para o mesmo setor analisado em diferente região geográfica. Sugerem-se, também, pesquisas que contemplem modelos rivais ou concorrentes ao proposto neste estudo para a aproximação do modelo teórico com a realidade.

Futuros estudos deverão se aprofundar mais nessa discussão para elucidar melhor a questão da estratégia baseada em programas de QVT no comprometimento afetivo das pessoas dentro das MPEs, bem como verificar se o modo de avaliação desse comprometimento não deva sofrer uma transformação, no sentido de melhor adequação das ações para melhoria da qualidade de vida e do maior envolvimento das pessoas com o negócio para seu maior desempenho e do desempenho empresarial.

Por fim, este trabalho procurou colaborar para o avanço do conhecimento em Qualidade de Vida no Trabalho nas MPEs, constituindo-se como mais um passo no sentido de trazer contribuições para futuras investigações sobre os temas relacionados à vida e ao crescimento do trabalhador e das empresas. A busca deste conhecimento é infinita, e dela depende o progresso da disciplina. Por esta razão, espera-se ter estimulado novas pesquisas e debates que envolvam QVT, em especial nas MPEs, extremamente em evidência para o nosso desenvolvimento sócioeconômico em face da crescente complexidade dos mercados. 


\section{Referências}

ALBUQUERQUE, L. G.; FRANÇA, A. C. L. Estratégias de Recursos Humanos e Gestão da Qualidade de Vida no Trabalho: O Stress e a Expansão do Conceito de Qualidade Total. Revista de Administração.USP. v.33, p.40-51. São Paulo.1998.

ALEXANDER, J. C. Sociología Cultural: Clasificación en sociedades complejas. Barcelona, Anthropos. 2000.

BARNEY, J.. Firm resources and sustained competitive advantage. Journal of management, v.17, n.1, p.99-120. 1991.

BAUGHN, C. C.; CAO, J. S. R.; LE, L. T. M.; LIM, V. A.; NEUPERT, K. E. Normative, social and cognitive predictors of entrepreneurial interest in China, Vietnam and Philippines. Journal of Developmental Entrepreneurship. v.11, n.1, p.57-77, Mar. 2006.

BURIGO, C. C. D. Qualidade de vida no trabalho: dilemas e perspectivas. Florianópolis, SC. Insular, p.184. 1997.

CONTADOR, J. C. Campos e armas da competição. São Paulo: Ed. Saint Paul, 2008.

CONTE, A. L. Funcionários com qualidade de vida no trabalho são mais felizes e produzem mais. Revista FAE Business, n.7, nov. 2003.

HAAK, M. K. Empregados Motivados: Empresas Triunfantes. São Paulo, Caderno de Pesquisas em Administração, v.1. 1995.

HAIR, J. F.; ANDERSON, R. E.; TATHAM, R. L. BLACK, W. C. Análise multivariada de dados.Porto Alegre. Bookman. 2005.

INTERNATIONAL PRODUCTIVITY CONGRESS. Better Quality of Work Life through Productivity. Japan. 1991.

LIMONGI-FRANÇA, A. C. Qualidade de Vida no Trabalho - QVT -São Paulo.Atlas. 2003

LIMONGI-FRANÇA, A.C.; ASSIS, M. P. Stress projetos de qualidade de vida no trabalho: caminhos percorridos e desafios. ERA Light. São Paulo. v.2, n.2. p.26-32. 1995.

MALHOTRA, N. K. Marketing research: an applied orientation. New Jersey: Prentice-Hall, 2001.

MINTZBERG, H. Managing: desvendando o dia a dia da gestão. Porto Alegre: Bookman, 2010.

MÖLLER, C. O lado humano da qualidade: maximizando a qualidade de produtos e serviços através do desenvolvimento das pessoas. São Paulo. Pioneira. 1997.

MYERS, J. E.; SWEENEY, T. J. Wellness in counseling: an overview. Alexandria, VA: American Counseling Association. 2007

PORTER, M. Estratégia Competitiva. Campus, 2005.

PRAHALAD, C. K. The fortune at the bottom of the pyramid. USA: Wharton School Publishing. 2004. 
SANT'ANNA, A. S.; MORAES, L. F. R.; KILIMNIK, Z. M. Competências individuais, modernidade organizacional e satisfação no trabalho: um estudo de diagnóstico comparativo. RAE, v. 4, n.1, jan./jul. 2005.

SEBRAE - Serviço Brasileiro de Apoio às Micro e Pequenas Empresas - O que pensam as Micro e Pequenas empresas sobre sustentabilidade. Disponível em: <http://www.sebrae.com.br/estudos-e-pesquisas>. Acesso em 30/14/2013.

SEBRAE - Serviço Brasileiro de Apoio às Micro e Pequenas Empresas - Pesquisa GEN $2014 . \quad$ Disponível em:

http://www.sebrae.com.br/sites/PortalSebrae/estudos_pesquisas/pesquisa-gem2014detalhe45,c9a1aabba6b6c410VgnVCM2000003c74010aRCRD>.Acesso em 13 de ago. de 2014.

VIEIRA, M. L. A contribuição das micro e pequenas empresas para redução da pobreza no Brasil. 2007. Dissertação de Mestrado- Universidade Federal do Ceará, Fortaleza. 2002.

WALTON, R. E. Quality of Working Life: What is it? Slow Management Review, v.15 p.1121. 1974.

WITMER \& SWEENEY. Holistic model for wellness and prevention over the life span.Journal of Counseling and Development. v.7, p.140-148. 1992. 
